\title{
非富勒烯有机光伏体系三线态损耗通道的分子氟化调控
}

占肖卫

北京大学材料科学与工程学院, 北京 100871

\section{Fluorination Effects on Triplet Loss Channels in Nonfullerene Organic Photovoltaic Systems}

\section{Xiaowei Zhan}

School of Materials Science and Engineering, Peking University, Beijing 100871, China.

Email: xwzhan@pku.edu.cn

Published online: April 19, 2021.

a

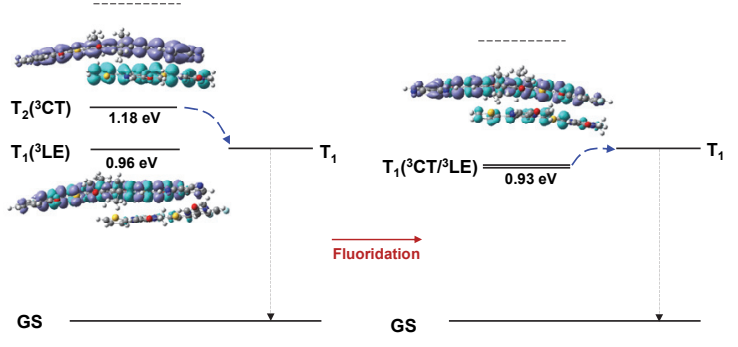

b
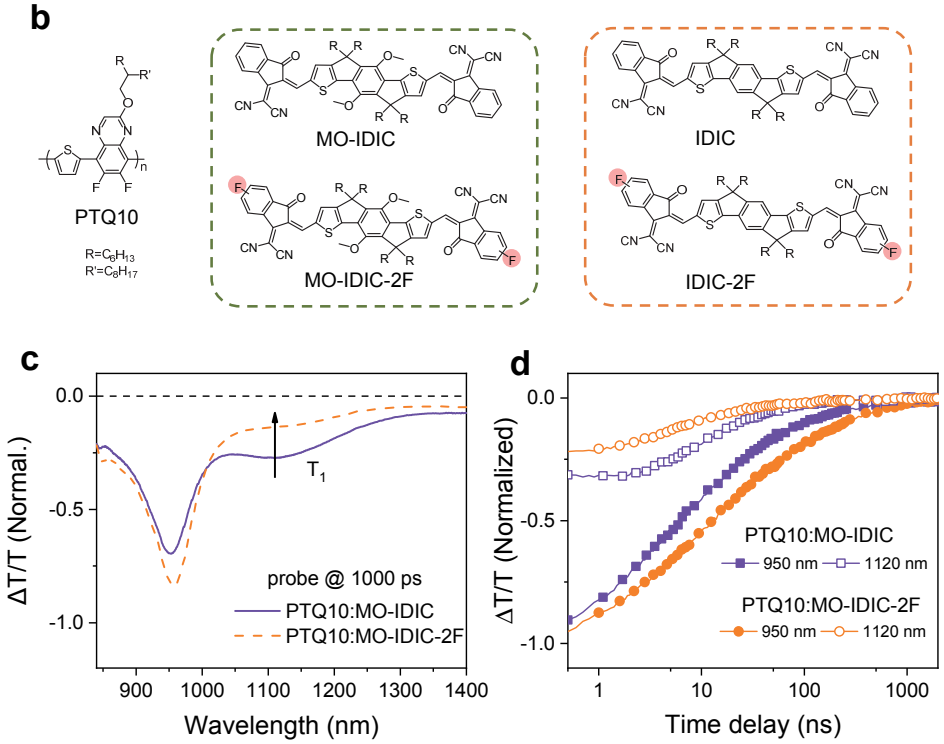

非富勒烯光伏系统三线态能级的受体氟化调控机制(a)。有机聚合物给体以及氟化和未氟化的非富勒烯受体分子结构(b)。 在氟化受体所构成的体异质结结构中, 三线态产生被抑制(c), 自由电荷具有更长的寿命(d)。

有机太阳能电池受益于非富勒烯受体的发 展, 能量转换效率已跃升至 $18 \%$ 左右 ${ }^{1}$, 器件效率
的进一步提升决定于光电荷产生、输运和收集过 程中的量子效率。光激发载流子的动力学过程的 
研究, 不仅能阐述基本工作原理, 也为器件优化提 供新思路。在有机给、受体共混体系中, 光激发单 线态激子拆分成的电子空穴, 通过双分子复合有 一定几率重新形成界面激子, 其中界面电荷转移 三线态 $\left({ }^{3} \mathrm{CT}\right)$ 通过系统中能量较低的三线态复合, 该自旋相关的损耗通道是有机器件区别于无机器 件的重要特征, 也是器件优化的主要挑战之一2。

最近, 南京大学物理学院张春峰/肖敏教授课 题组联合化学化工学院马晶教授和北京化工大学 张志国教授, 实验和理论合作研究表明, 非富勒烯 受体光伏体系中, 三线态损耗可以借助受体氟化 抑制(图a)。研究人员采用超快光谱学实验结合量 子化学计算的方法, 研究了给体PTQ10和模型受 体分子IDIC和MO-IDIC的给受体共混体系中(图b) 的激发态动力学过程。光谱学实验结果清晰显示 双分子复合产生三线态的光谱特征, 在氟化受体 的体系中, 三线态产生显著抑制(图c), 载流子的 寿命明显延长(图d); 理论计算表明在给受体的界 面处, 氟化受体分子和给体分子更强的耦合导致 界面处的电荷转移三线态 $\left({ }^{3} \mathrm{CT}\right)$ 和受体中的局域三 线态 $\left({ }^{3} \mathrm{LE}\right)$ 发生杂化, 界面处的三线态能量降低, 抑制了从界面到受体分子的三线态能量转移过 程, 从而减少了三线态复合损耗。研究结果解释了 器件优化受体氟化策略的内在机制, 为抑制器件 损耗提供了新的思路, 上述相关研究成果近期发表

在Journal of the American Chemical Society 上 $^{3}$ 。

非富勒烯受体在近红外光谱段有很强的吸收, 动力学机制也展现了与富勒烯受体体系不一样的
特征。研究组与多方合作研究了约200多不同给受 体组合, 观察到低界面驱动能下高效的空穴转移 ${ }^{4}$, 揭示了聚合物受体中构型依赖的电荷转移激发态 主导的空穴转移通道 ${ }^{5}$; 最近, 在典型PM6/Y6 体系 中, 研究组观察到由分子间相互作用, 受体畴内激 发态媒介的电荷分离过程6。电荷分离过程的阐述 对理解分子聚集态的光物化机制, 理解非富勒烯 受体光伏的工作原理具有重要意义, 也将为器件 的进一步优化提供重要依据。

\section{References}

(1) Best research-cell efficiency chart. https://www.nrel.gov/pv/cellefficiency.html (accessed April 5, 2021).

(2) Rao, A.; Chow, P. C.; Gelinas, S.; Schlenker, C. W.; Li, C. Z.; Yip, H. L.; Jen, A. K.; Ginger, D. S.; Friend, R. H. Nature 2013, 500 (7463), 435. doi: 10.1038/nature12339

(3) Wang, R.; Xu, J.; Fu, L.; Zhang, C.; Li, Q.; Yao, J.; Li, X.; Sun, C.; Zhang, Z. G.; Wang, X.; Li, Y.; Ma, J.; Xiao, M. J. Am. Chem. Soc. 2021, 143 (11), 4359. doi: 10.1021/jacs.0c13352

(4) Bin, H.; Gao, L.; Zhang, Z. G.; Yang, Y.; Zhang, Y.; Zhang, C.; Chen, S.; Xue, L.; Yang, C.; Xiao, M.; Li, Y. Nat. Commun. 2016, 7, 13651. doi: $10.1038 /$ ncomms 13651

(5) Wang, R.; Yao, Y.; Zhang, C.; Zhang, Y.; Bin, H.; Xue, L.; Zhang, Z. G.; Xie, X.; Ma, H.; Wang, X.; Li, Y.; Xiao, M. Nat. Commun. 2019, 10 (1), 398. doi: 10.1038/s41467-019-08361-4

(6) Wang, R.; Zhang, C.; Li, Q.; Zhang, Z.; Wang, X.; Xiao, M. J. Am. Chem. Soc. 2020, 142 (29), 12751. doi: 10.1021/jacs.0c04890 